\title{
Health-Promoting and Health-Risk Behaviors: Theory-Driven Analyses of Multiple Health Behavior Change in Three International Samples
}

\author{
Sonia Lippke • Claudio R. Nigg • Jason E. Maddock
}

Published online: 14 January 2011

(C) The Author(s) 2011. This article is published with open access at Springerlink.com

\begin{abstract}
Background Co-occurrence of different behaviors was investigated using the theoretical underpinnings of the Transtheoretical Model, the Theory of Triadic Influence and the concept of Transfer.

Purpose To investigate relationships between different health behaviors' stages of change, how behaviors group, and whether study participants cluster in terms of their behaviors.

Method Relationships across stages for different behaviors were assessed in three studies with $N=3,519,965$, and 310 individuals from the USA and Germany by telephone and internet surveys using correlational analyses, factor analyses, and cluster analyses.

Results Consistently stronger correlations were found between nutrition and physical activity $(r=0.16-0.26, p<$ $0.01)$ than between non-smoking and nutrition $(r=0.08-$ $0.16, p<0.03$ ), or non-smoking and physical activity $(r=$ 0.01-0.21). Principal component analyses of investigated
\end{abstract}

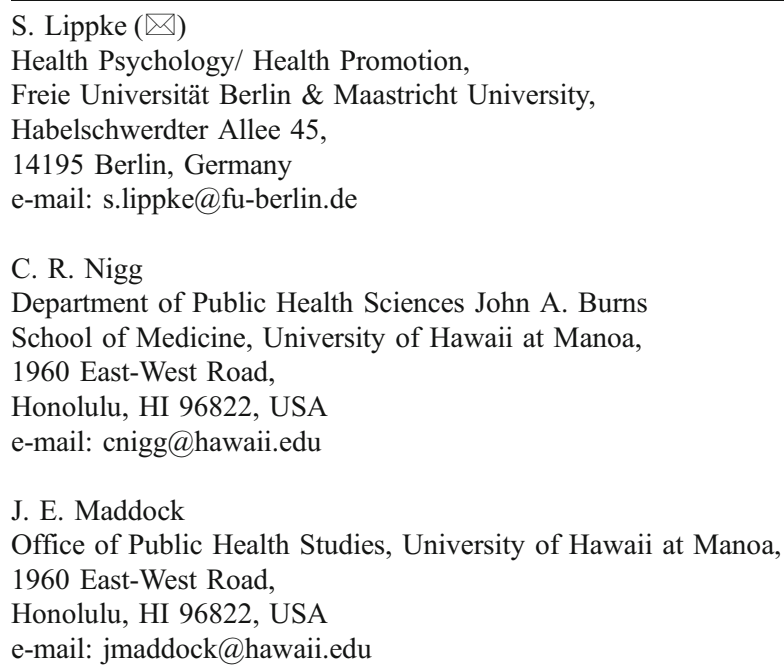

behaviors indicated two factors: a "health-promoting" factor and a "health-risk" factor. Three distinct behavioral patterns were found in the cluster analyses.

Conclusion Our results support the assumption that individuals who are in a higher stage for one behavior are more likely to be in a higher stage for another behavior as well. If the aim is to improve a healthy lifestyle, success in one behavior can be used to facilitate changes in other behaviors-especially if the two behaviors are both health-promoting or health-risky. Moreover, interventions should be targeted towards the different behavioral patterns rather than to single behaviors. This might be achieved by addressing transfer between behaviors.

Keywords Transfer $\cdot$ Stage $\cdot$ Nutrition $\cdot$ Physical exercise $\cdot$ Non-smoking

\section{Introduction}

Populations with multiple behavioral risk factors are at greatest risk for chronic disease and premature death compared to people with single or no behavioral risk factors, and also account for a disproportionate percentage of health care costs [1]. Thus, understanding multiple health behavior change and its mechanisms is imperative to help people to adopt and maintain as many as possible recommended health behaviors $[2,3]$.

There are different strategies to examine multiple behaviors. One might (a) explore the behaviors the individuals perform and whether they are interrelated. One might also (b) analyze whether there are groups of individuals which show comparable risk behaviors and health behaviors. This paper will address both questions across three theoretical models. 


\section{Transtheoretical Model}

How people change their behaviors can be described by the stages of change which are core concept of the Transtheoretical Model (TTM; [4]). The TTM proposes five stages which individuals move through when deciding and actually changing their behaviors. The first stage is the precontemplation stage (PC) in which individuals do not consider behavior change in the near future. In the contemplation stage $(\mathrm{C})$, individuals consider performing health behavior but have not yet decided to change. In the preparation stage $(\mathrm{P})$, individuals prepare and plan the actual behavior change. In the action stage (A), behavior is initiated. When behavior is performed and consolidated for a longer time, the maintenance stage (M) is reached [4].

Using the stage concept to investigate different behaviors has the advantage of addressing behavior change not only as a dichotomous process (at-risk or not), but to model the dynamic aspect of behavior change by including behavior and intention at the same time. This is important if more than one behavior is investigated: if one is ready to change one behavior, one might consider changing another behavior as well. In other words, some aspects of changing one behavior may influence the modification of other behaviors: motivation, action steps, or confidence to self-regulate may be transferred to other behavior change efforts. Cross-sectionally, this may be observed in terms of correlations between stages for different behaviors (e.g., [5]). Similarities between different health behaviors and their co-occurrence might be explained by the Theory of Triadic Influence (TTI, [2]) and Transfer [6], both described in the following.

\section{Theory of Triadic Influence}

In the TTI, Flay and Petraitis [2] conceptualized that some behaviors are closely related due to very similar etiologies and experiences. According to the TTI, some behaviors might be similar in terms of their social-cognitive determinants such as behavioral consequences, e.g., physical activity and nutrition might both serve to maintain a healthy body weight, whereas alcohol and nicotine might be used to regulate emotions. Thus, it is conceivable that behaviors might be clustered into health-risk behaviors (which need to be reduced such as alcohol and nicotine consumption) and health-promoting behaviors (which need to be adopted such as physical activity and nutrition). These behaviors might then be bundled and addressed concurrently in interventions. For some behaviors, individuals may be further along in the change process (e.g., not smoking any more or preparing to do so) which might enable changing other unhealthy habits as well. This can theoretically be explained with transfer effects.

\section{Transfer Theory}

Transfer is the process when lessons learned in one context are applied to another context. This can only be performed if one has the capacity to apply acquired competences to other domains $[6,7]$. Individuals may transfer their knowledge and experiences from one behavior change to another if the domains share enough similarities [8]. If two behaviors are very different in their nature - such as reducing smoking and adopting physical activity - transfer may be less likely than if two behaviors are similar in terms of planning the adoption and integration of the new behavior into daily life [9].

Typically, transfer is studied in interventions that target one behavior, and the occurrence of any transfer is assessed in other behaviors. For example, in an intervention by Mata et al. [10], an intervention to increase their physical activity behavior was provided to obese women. Transfer was expected in terms of not only improved physical activity but also women's eating behavior. The intervention group did increase the targeted variables (activity, motivation, and weight loss) and also eating regulation. Unfortunately, in the study by Mata et al. [10], actual eating behavior was not reported. Also, many other studies have failed to show behavioral transfer effects $[11,12]$. In contrary, other studies did show that transfer occurred. Interventions targeting one behavior facilitated changes in another behavior $[13,14]$.

Some interventions such as the one by Prochaska et al. [15] targeting multiple behaviors were effective in changing all targeted behaviors (in comparison to a control group). However, not all interventions addressing multiple behaviors have been successful in changing all targeted behaviors (e.g., $[16,17])$. There are many possible reasons for this failure. Maybe only single behaviors were successfully targeted in the intervention, and the others were not successfully matched and consequently not improved. Another reason could be that the behaviors were too different (in terms of the TTI) and that the attempt to change them failed because of cognitive overload. In terms of possible transfer effects, both explanations would also mean that no or too little transfer from the successfully changed behavior occurred to the other behaviors. Thus, the question is, which behaviors might be easier to be changed in concert, i.e., which behaviors are more correlated and which appear rather independent?

\section{Interrelations of Different Single Health Behaviors}

Generally, behaviors cluster together [18-20]. However, some behaviors interrelate more than others in accordance with the TTI. High correlations have been found between diet and exercise $(r=0.36 ;[21] ; r=0.14 ;[5])$, and smoking and alcohol consumption $(r=0.35$; [5]). In contrast, associations 
between non-smoking and physical activity or intake of fruit and vegetables were not detected [22]. Low or no correlations were found between alcohol consumption and diet $(r=-0.06$; [5]), alcohol consumption and physical activity $(r=0.05$; [5]), physical activity and non-smoking $(r=0.11 ;[23] ; r=-0.09$; [5]), or diet and smoking ( $r=-0.11$; [5]).

Abrantes et al. [24] found that adolescents who have made a tobacco quit attempt were more likely to be on a sports team but not more likely to be physically active. However, a successful quit attempt was not related to exercise or being in a sports team, but to alcohol use. Adolescents who drank alcohol were $66 \%$ less likely to make a successful quit attempt [24]. These findings direct to a general pattern which is in line with the TTI [2] that health-promoting behaviors are correlated with each other and load on one factor, and health-risk behaviors are associated and load on another factor.

This was also supported in a study by Van Nieuwenhuijzen et al. [25] which found that behaviors from different domains are only weakly related. Verkooijen et al. [26] found in 16-22-year-old adolescents that physical activity was not related to preventing smoking initiation. Interestingly, in women who used physical activity to lose weight, the likelihood to start smoking increased.

Behavioral antecedents can also interrelate. Kremers et al. [27] found that intentions and other social-cognitive factors determining physical activity and nutrition correlated higher than the behaviors themselves, which is in line with the TTI. The authors speculated about underlying processes such as stages; however, they did not investigate stages, which will be done in the current research.

\section{Clusters of Individuals with Similar Health Behaviors}

Individuals might be clustered regarding their behaviors. In a student sample, Dodd et al. [28] found three clusters: an "unhealthy/high risk" cluster, a "moderately healthy/moderate risk" cluster, and a "healthy/low risk" cluster.

Quintiliani et al. [29] investigated more quantitative characteristics of behaviors and found three clusters in young women: a group showing few "health-promoting behaviors" and many "health-risk behaviors", a group reporting generally few behaviors (both domains), and a group with many health-promoting behaviors and medium health-risk behaviors. This pattern might be explained by transfer in that sense that third group managed to adopt health-promoting behaviors and maybe transferred these changes also to reduce risk behaviors. In contrary, the first groups failed to perform any health-promoting behaviors and to reduce the risk behaviors (no positive transfer at all).

DeVries et al. [30] revealed three clusters in a large sample. One group was labeled as unhealthy cluster performing few health-promoting behaviors and many health-risk behaviors. Another group was named the healthy cluster with opposite patterns. The third group was performing selected health-promoting behaviors (physical activity, but no fruit and vegetable consumption) and low health-risk behaviors. This finding is important with respect to potential transfer. It seems that some people are able to transfer successful change to other behaviors regardless of whether they are also health-promoting or risky for their health. Conversely, some people appear as not successful with any behavior change. Finally, there seems to be a group that transfers reduction of health-risk behaviors to physical activity (or vice versa) but not with nutrition-related behaviors. Concluding, in numerous studies that grouped people according to their behaviors, three clusters of study participants were found.

\section{Aims of the Three Studies}

Transfer and behavioral similarities should be indicated by correlations, factorial structures, and clusters of individuals exhibiting similar behaviors. In particular, we hypothesize: (1) high correlations of behaviors should be observable within related behaviors, i.e., within "health-promoting behaviors" and within "health-risk behaviors"; low correlations are expected between behaviors which are "healthpromoting" and behaviors that are "health-risky"; (2) "health-promoting behaviors" will load on one factor and "health-risk behaviors" on another; finally, (3) different groups according to their health and risk behaviors are expected to emerge with distinct behavioral patterns.

\section{Data Analysis}

Hypotheses were tested in three different international studies. The studies are presented with their particular methods and results. Contingencies across behaviors (hypothesis 1) were analyzed using stage questions as an ordinal rank variable, and computing non-parametric correlations across behaviors. Dimensional analyses (hypothesis 2) were performed with Principle Components Analysis using Varimax Rotation. Grouping analyses (hypothesis 3) were done with two-step cluster analysis. Clusters were identified using log-likelihood distances. For cluster confirmation, numbers of clusters to be determined were constrained to three. Every participant belonged to one and only one cluster. Clusters were examined with the Model View Output (Model Viewer in SPSS, see Figs. 1, 2, and 3).

For reporting prevalences, never-smokers were included. For all correlational and factor analyses, never-smokers were excluded as they do not represent part of the behavior 
Fig. 1 Groups generated with two-way cluster analysis (study 1). Background dark blue Importance=1 (Stage F\&V; Smoking); light blue Importance= 0.09 (Stage PA); bars in the rows of Feature represent frequencies for the stages (PC, C, P, A, M for fruit and vegetable as well as $\mathrm{PA}$, and $\mathrm{PC}, \mathrm{C}, \mathrm{P}, \mathrm{A}, \mathrm{M}$, neversmokers for non-smoking)
Clusters

Feature Importance

$\square 1.0 \square 0.8 \square 0.6 \square 0.4 \square 0.2$

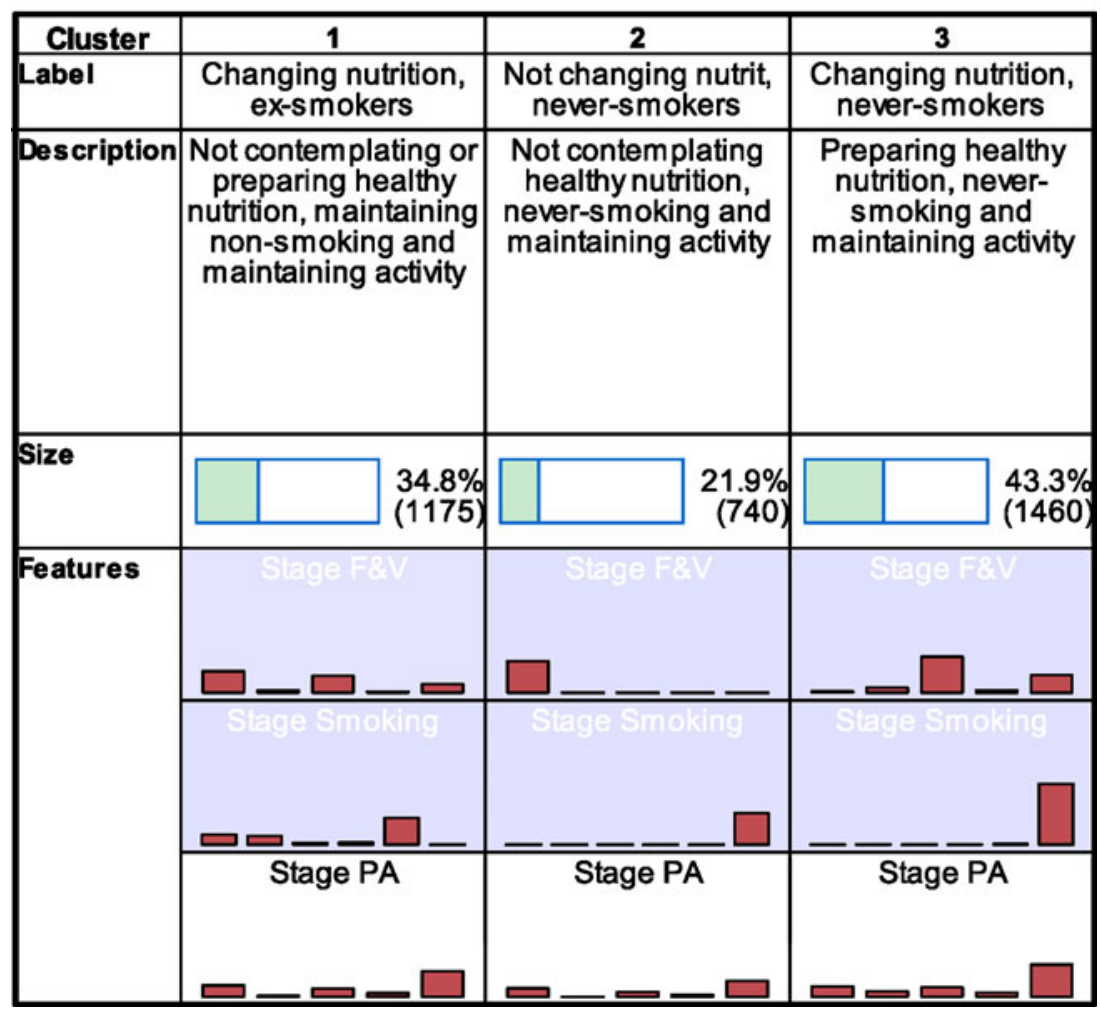

change process. For the cluster analyses, never-smokers were included, to keep as many individuals as possible in the sample, and as the cluster analyses used this variable as categorical and not as ordinal variable [31]. All analyses were run using SPSS 18.

\section{Study 1-Telephone Survey in Hawaii (USA)}

Method

\section{Participants}

The sample of $N=3,519$ study participants consisted of $2,122(60.3 \%)$ women. Participants were between 18 and 91 years, $M=46.31, \mathrm{SD}=16.31$. Only 167 (4.7\%) had less than a high school degree, 985 (28\%) had only a high school degree, 969 (27.5\%) some college, and 1,386 (39.4\%) graduated college.

\section{Procedure}

A survey using random digit dialing of Hawaii's noninstitutionalized adult population was conducted by trained interviewers, supported by a computer-assisted telephone interview system. The University of Hawaii Committee on Human Subjects approved procedures, and informed consent was obtained over phone (for further information, see references [32, 33]).

\section{Measurements}

Physical Activity Stage Participants were classified into one of five stages; precontemplation (PC): do not engage in regular exercise and have no intention of doing so in the next 6 months; contemplation $(\mathrm{C})$ : do not engage in regular exercise, but intend to do so in the next 6 months; preparation $(\mathrm{P})$ : do not engage in regular exercise, but intend to do so in the next month; action (A): currently engaging in regular exercise, but for less than 6 months; maintenance $(\mathrm{M})$ : currently engaging in regular exercise for 6 months or more. Regular exercise was defined as any activity that makes your heart beat faster and/or makes you breathe harder, such as walking briskly, biking, swimming, paddling, and aerobics classes. The term "regular" exercise was defined as at least four times per week for at least 30 min each day at the above-mentioned intensity or higher. The measure was validated by Hellsten et al. [34]. 
Fig. 2 Groups generated with two-way cluster analysis (study 2). Background color Importance $=1$ (Stage PA); Importance= 0.75 (Stage Healthy Diet); Importance $=0.71($ Stage $F \& V)$; Importance $=0.21$ (Stage Drinking); Importance $=0.01$ (Stage Smoking); bars in the rows of Feature represent frequencies for the stages (PC, C, P, A, M for all behaviors excepts smoking, and $\mathrm{PC}, \mathrm{C}, \mathrm{P}, \mathrm{A}, \mathrm{M}$, neversmokers for non-smoking)

\section{Clusters}

Feature Importance

$1.0 \square 0.8 \square 0.6 \square 0.4 \square 0.2$

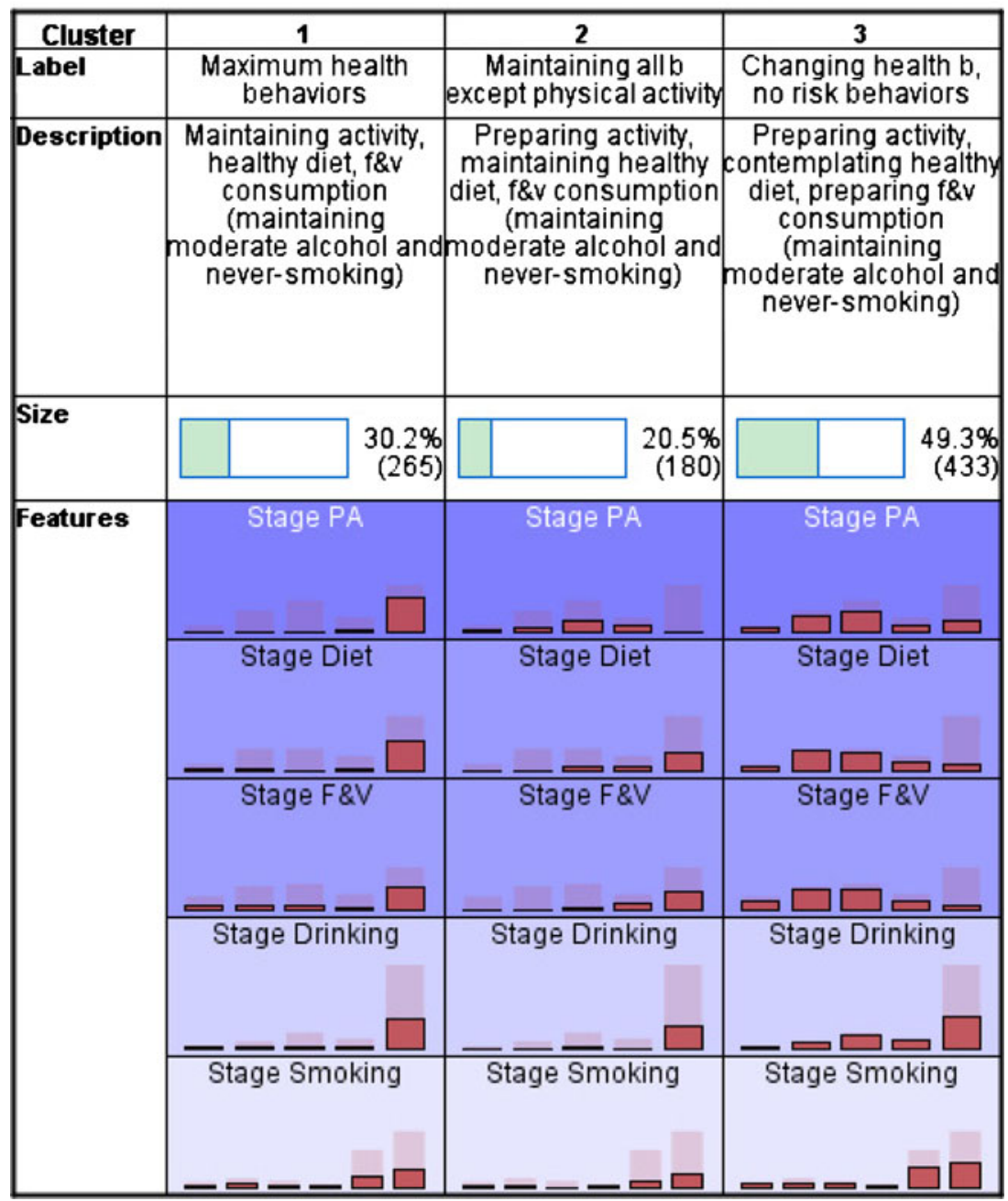

Fruit and Vegetables Consumption Stage Participants were asked about their fruit and vegetable intake and their intention to consume five or more servings per day. They were classified into one of the five stages; PC: do not eat five-a-day, with no intention to do so in the next 6 months; $\mathrm{C}$ : do not eat five-a-day, but intend to do so in the next 6 months; P: do not eat five-a-day, but intend to in the next month; A: currently eating five-a-day, but for less than 6 months; M: currently eating five-a-day for more than 6 months. The measure was validated by Greene at al. [35].

Non-smoking stage was assessed by asking about participants' current and past smoking habits and by questioning the smokers about their intentions to quit. Participants were classified into one of six stages; PC: smoker with no intention to quit in the next 6 months; $\mathrm{C}$ : smoker with intention to quit within the next 6 months; P: smoker with intention to quit within a month; A: ex-smokers who quitted within the last 6 months; M: ex-smokers who quitted more than 6 months ago; and never-smokers (less than 100 cigarettes smoked during lifetime). The measure was validated by previous research (e.g., [4, 19]).

\section{Results}

\section{Stage Distribution}

The sample had the following stage distribution for physical activity PC, 730 (20.7\%), C, 157 (4.5\%); P, 556 (15.8\%); A, 240 (6.8\%); M, 1,779 (50.6\%), for fruit and vegetable consumption PC, 1,298 (36.9\%); C, 177 (5.0\%); P, 1,255 (35.7\%); A, 80 (2.3\%); M, 615 (17.5\%), and for non-smoking PC, 255 (7.2\%); C, 233 (6.6\%); P, 50 (1.4\%); A, 53 (1.5\%); M, 676 (19.2\%). Additionally, 2,252 (64.0\%) reported that they had never smoked. 
Fig. 3 Groups generated with two-way cluster analysis (study 3 ). Background color Importance $=1$ (Stage Smoking); Importance= 0.62 (Stage Foot Checking); Importance $=0.46($ Stage $F \& V)$; Importance $=0.20($ Stage $P A)$; Importance $=0.01$ (Stage Alcohol); bars in the rows of Feature represent frequencies for the stages (PC, C, P, A, M for all behaviors excepts smoking, and PC, C, P, A, M, never-smokers for non-smoking)

\section{Clusters}

Feature Importance

$\square$ 1.0E0 $\square$ 8.0E-1 $\square 6.0 \mathrm{E}-1 \square 4.0 \mathrm{E}-1 \square 2.0 \mathrm{E}-1$

\begin{tabular}{|c|c|c|c|}
\hline Cluster & 1 & 2 & 3 \\
\hline Label & $\begin{array}{l}\text { Changing health } \\
\text { behaviors, no risk b }\end{array}$ & $\begin{array}{c}\text { Maintaining all } \\
\text { behaviors }\end{array}$ & $\begin{array}{l}\text { Maximum health } \\
\text { behaviors }\end{array}$ \\
\hline Description & $\begin{array}{l}\text { Never-smokers, } \\
\text { contemplation foot- } \\
\text { checking, healthy } \\
\text { nutrition and physical } \\
\text { activity (maintaining } \\
\text { moderate alcohol } \\
\text { consumption) }\end{array}$ & \begin{tabular}{c|} 
Ex-smokers, \\
maintaining foot- \\
checking, healthy \\
nutrition and physical \\
activity (maintaining \\
moderate alcohol \\
consumption)
\end{tabular} & $\begin{array}{l}\text { Never-smokers, } \\
\text { maintaining foot- } \\
\text { checking, healthy } \\
\text { nutrition and physical } \\
\text { activity (maintaining } \\
\text { moderate alcohol } \\
\text { consumption) }\end{array}$ \\
\hline Size & $\begin{array}{r}36.9 \% \\
(110)\end{array}$ & $\begin{array}{r}28.2 \% \\
(84)\end{array}$ & $\begin{array}{r}34.9 \% \\
(104)\end{array}$ \\
\hline \multirow[t]{5}{*}{ Features } & 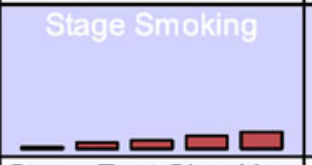 & Slage Smoking & Shages Sinching \\
\hline & Stage Foot Checking & Stage Foot Checking & Stage Foot Checking \\
\hline & 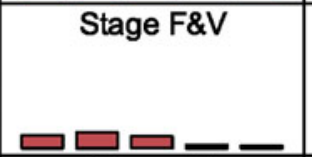 & $\begin{array}{c}\text { Stage F\&V } \\
\square \square\end{array}$ & - \\
\hline & $\square \square$ & $=\square$ & Stage PA \\
\hline & Stage Alcohol & Stage Alcohol & Stage Alcohol \\
\hline
\end{tabular}

\section{Relationships of Stages Across Different Behaviors}

Using the stage question as an ordinal, rank variable, nonparametric correlations were computed (see Table 1, upper part). Testing how the three behaviors load on different factors is presented in Table 1, lower part. The rotated component matrix (converging after three iterations) revealed two rotated factors, which explained $38.3 \%$ of the variance (first factor) and $33.8 \%$ of the variance (second factor). As reported in Table 1, the two healthpromoting behaviors loaded on the first factor, and nonsmoking loaded on the second factor. A confirmatory analysis (forcing two factors, detailed results not shown) validated the exploratory analysis and revealed similar results.
Clusters of Study Participants

The two-way cluster analysis generated three groups which contained between $21.9 \%$ and $43.3 \%$ of the included study participants (see Fig. 1) and an Average Silhouette of 0.2 (borderline acceptable cohesion and separation). Both nutrition and smoking were equally important predicting the group allocation with much differences between the groups (stages regarding nutrition in group 1, PC, 43\%; $\mathrm{C}$, $4.9 \%$;, $33.4 \%$; $\mathrm{A}, 1.9 \%$, and $\mathrm{M}, 16.9 \%$; in group $2, \mathrm{PC}$, $100 \%$; in group 3, PC, 2.2\%; C, 7.9\%; P, 58\%; A, 3.8\%, and $\mathrm{M}, 28.1 \%$. Stages regarding smoking in group $1, \mathrm{PC}$, $20.3 \%$; C, 18\%; P, 4\%; A, 4.2\%; M, 53.5\%; never-smokers, $0 \%$; in group 2, never-smokers, $100 \%$; in group 3, PC, $0.5 \% ; \mathrm{C}, 0.4 \% ; \mathrm{P}, 0.0 \% ; \mathrm{A}, 0.2 \%, \mathrm{M}, 1.2 \%$, and never- 
Table 1 Study 1 - Spearman-rho correlations between the five stages across three behaviors

\begin{tabular}{lllll}
\hline & & Physical activity stage & Fruit and vegetable consumption stage $^{\text {Non-smoking Stage }^{\mathrm{a}}}$ \\
\hline Physical activity stage & $r$ & 0.16 & 0.08 \\
& $p$ & $<0.01$ & 0.01 \\
& $N$ & 3,375 & 1,241 \\
Fruit and vegetable consumption stage & $r$ & & 0.16 \\
& $p$ & & $<0.01$ \\
Factor loading on factor 1 & $N$ & & 0.70 & 1,229 \\
Factor loading on factor 2 & & 0.81 & - & - \\
\hline
\end{tabular}

${ }^{a}$ Never-smokers excluded

${ }^{b}$ Factor loadings below 3 are suppressed (VARIMAX rotated principal component factor analysis); results are invariant if non-smokers are included as sixth group (reported results for five stage groups across all the behaviors only)

smokers, 97.7\%). Physical activity was less important and almost all stage distributions were similar across groups (in group 1, PC, 23\%; C, 2\%; P, 16.5\%; A, 7.5\%, and $\mathrm{M}$, $51.1 \%$; in group 2, PC, 27.3\%; C, $0 \%$; P, 16.1\%; A, 5.9\% and $\mathrm{M}, 50.7 \%$; in group $3, \mathrm{PC}, 16.6 \%$; C, $8.8 \%$; P, $16.1 \%$; A, 5.9\%, and M, 50.7\%).

Based on the characteristic stage frequencies within the cluster groups, they were labeled according to the behavior with variance across the groups (nutrition and smoking): individuals in group 1 were those who were changing their nutrition and not smoking any more. Those in group 2 did not intend to change their nutrition and never smoked, and individuals in group 3 were changing their nutrition and never smoked (see Fig. 1).

\section{Study 2-Online Study in German-Speaking Countries}

\section{Method}

\section{Participants}

The sample of $N=965$ study participants consisted of 638 (66.1\%) women. Participants were between 15 and 81 years, $M=39.21, \mathrm{SD}=12.74$. Only $110(8.3 \%)$ individuals had less than a high school degree. Overall, 240 (24.6\%) reported some college, 375 (38.9\%) graduated college.

\section{Procedure}

German-speaking internet users were assessed in an online study, which was conducted using the software dynQuest [36]. After the study was introduced, participants provided informed consent and followed a link to a self-administered questionnaire. The Freie Universität Berlin approved procedures.

\section{Measurements}

The assessment of stage was a refinement of the algorithm previously developed for exercise and diet (see "Study 1Telephone Survey in Hawaii (USA)") adapted to Germanspeaking populations [37].

Physical activity stage was measured asking study participants, "Please think about your typical week: Did you engage in physical activity at least 5 days per week for $30 \mathrm{~min}$ or more (or $2.5 \mathrm{~h}$ during the week), in such a way that you were moderately exhausted?" Regarding fruit and vegetable consumption stage, the question was: "Please think about what you have typically consumed during the last week: Did you eat five portions of fruit and vegetables per day?" The measurement was validated by Maddock et al. [37]. The balanced diet stage was measured with the instruction: "Do you eat a balanced diet on a typical day? A balanced diet consist of different other aspects additionally to fruit and vegetables. Particularly, the five facets are: (1) choice and appropriate amounts of overall calories, (2) plenty of whole grains and potatoes, (3) moderate amounts of meat, meat products, and eggs, (4) decrease fat and fatty foods, (5) limited sugar and salt intake." Additionally, healthy drinking stage was assessed with "Please think about what you typically drink. Do you drink 1.51 of nonalcoholic and not caffeinated beverage (water, juice, fruit and herbal tea) during the day?"

For all behaviors, the instructions were: "Please choose the statement that describes you best." Participants responded to a rating scale with verbal anchors "No, and I do not intend to start" (PC), "No, but I am considering it" (C), "No, but I seriously intend to start" (P), "Yes, but only for a brief period of time" (A), and "Yes, and for a long period of time" (M).

Non-smoking stage was assessed by asking about participants' current and past smoking habits and by 
questioning smokers about their intentions to quit. Participants were classified into one of six stages; PC: smoker with no intention to quit; C: smoker, who consider to quit; $\mathrm{P}$ : smoker with strong intention to quit; A: quit within the last 6 months; M: quit more than 6 months ago; and neversmokers $[4,19]$.

Results

\section{Stage Distribution}

The stage distribution for physical activity was PC, 50 (5.2\%); C, 165 (17.1\%); P, 252 (26.1\%); A, 116 (12.0\%); $\mathrm{M}, 360$ (37.3\%), for fruit and vegetable consumption PC, 99 (10.3\%), C, 181 (18.8\%); P, 194 (20.1\%); A, 117 (12.1\%); M, 325 (33.7\%), for non-smoking PC, 49 (5.1\%); C, 81 (8.4\%); P, 55 (5.7\%); A, 32 (3.3\%); M, 295 (30.6\%) and $444(46 \%)$ never-smokers, for healthy drinking stage PC, 22 (2.3\%); C, 61 (6.3\%); P, 133 (13.8\%); A, 80 (8.3\%); M, 656 (68.0\%) and for balanced diet, PC, 53 (5.5\%); C, 164 (17.0\%); P, 166 (17.2\%); A, 108 (11.2\%); M, 405 (42.0\%).

\section{Relationships of Stages Across Different Behaviors}

The non-parametric correlations between all behaviors are reported in the Table 2. The rotated component matrix (converging after three iterations) revealed two rotated factors which explained $34.4 \%$ of the variance (first factor) and $21.3 \%$ of the variance (second factor).
As reported in Table 2, the four health-promoting behaviors loaded on one factor and non-smoking loaded on the other factor. The confirmatory analysis (forcing two factors) validated exploratory analysis and revealed similar results.

\section{Clusters of Study Participants}

The two-way cluster analysis generated three groups which contained between $20.5 \%$ and $49.3 \%$ of the included study participants (see Fig. 2) and an Average Silhouette of 0.3 (fair cohesion and separation). Physical activity was the most important variable predicting the group allocation (stage regarding physical activity in group $1, \mathrm{PC}, 0.4 \%$; , $1.1 \%$; $\mathrm{P}, 0 \%$; $\mathrm{A}, 3.4 \%$, and $\mathrm{M}, 95.1 \%$; in group $2, \mathrm{PC}$, $7.8 \%$; C, $16.7 \%$; $\mathrm{P}, 48.3 \%$; A, $27.2 \%$, and $\mathrm{M}, 0 \%$; in group 3, PC, $7.9 \%$;, $27.9 \%$; P, 32.8\%; A, $11.1 \%$, and $\mathrm{M}$, $20.3 \%)$. The two nutrition-related behaviors were of second and third importance, followed by drinking and smoking (for stage frequencies, see Fig. 2; detailed numbers can be obtained from the authors).

Based on the characteristic stage frequencies within the cluster groups, they were labeled according to the behavior with variance between the groups: individuals in group 1 were those who showed a very healthy lifestyle across behaviors. Those in group 2 were preparing their physical activity and adopting or maintaining all other behaviors. Individuals in group 3 were contemplating or preparing to change their health behaviors and not performing the assessed risk behavior (see Fig. 2).

Table 2 Study 2 - Spearman-rho correlations between the five stages across five behaviors

\begin{tabular}{|c|c|c|c|c|c|c|}
\hline & & $\begin{array}{l}\text { Physical activity } \\
\text { stage }\end{array}$ & $\begin{array}{l}\text { Fruit and vegetable } \\
\text { consumption stage }\end{array}$ & $\begin{array}{l}\text { Balanced diet } \\
\text { stage }\end{array}$ & $\begin{array}{l}\text { Healthy drinking } \\
\text { stage }\end{array}$ & $\begin{array}{l}\text { Non-smoking } \\
\text { stage }\end{array}$ \\
\hline \multirow[t]{3}{*}{ Physical activity stage } & $r$ & & 0.18 & 0.26 & 0.16 & 0.01 \\
\hline & $p$ & & $<0.01$ & $<0.01$ & $<0.01$ & 0.68 \\
\hline & $N$ & & 911 & 890 & 935 & 938 \\
\hline \multirow{3}{*}{$\begin{array}{l}\text { Fruit and vegetable } \\
\text { Consumption stage }\end{array}$} & $r$ & & & 0.40 & 0.27 & 0.15 \\
\hline & $p$ & & & $<0.01$ & $<0.01$ & $<0.01$ \\
\hline & $N$ & & & 894 & 908 & 913 \\
\hline \multirow[t]{3}{*}{ Balanced diet stage } & $r$ & & & & 0.21 & 0.08 \\
\hline & $p$ & & & & $<0.01$ & 0.02 \\
\hline & $N$ & & & & 888 & 893 \\
\hline \multirow[t]{3}{*}{ Healthy drinking stage } & $r$ & & & & & -0.01 \\
\hline & $p$ & & & & & 0.91 \\
\hline & $N$ & & & & & 946 \\
\hline Factor loading on factor $1^{\mathrm{a}}$ & & 0.59 & 0.69 & 0.71 & 0.62 & - \\
\hline Factor loading on factor $2^{\mathrm{a}}$ & & - & 0.33 & - & - & 0.94 \\
\hline
\end{tabular}

${ }^{\mathrm{a}}$ Never-smokers excluded. Factor loadings below 3 are suppressed (VARIMAX rotated principal component factor analysis) 


\section{Study 3-Online Study for Individuals with Diabetes in German-Speaking Countries}

Method

\section{Participants}

The sample contained $N=310$ study participants and consisted of $159(58.5 \%)$ women. The majority $(n=281$; $90.6 \%$ ) of the total sample had type 1 diabetes; 20 individuals reported to have type 2 diabetes $(6.5 \%)$, and the remaining 9 study participants $(2.9 \%)$ had another type of diabetes such as LADA, MODY, or gestational diabetes. Participants were between 18 and 75 years, $M=43.52, \mathrm{SD}=$ 13.58. Ninety-six (31\%) held a high school degree, 161 $(51.9 \%)$ some college, and $73(23.5 \%)$ graduated college.

\section{Procedure}

Customers of diabetic products were recruited via a printed and an online-journal of a diabetes company $(n=157$, $50.6 \%$ and $n=50,16.1 \%$, respectively). Further, $n=44$ $(14.2 \%)$ individuals joined the study due to an internet search. Remaining study participants were referred by other sources such as friends who told them about the study. The questionnaire was provided online and data were collected using the software dynQuest [36]. After the study was introduced, participants provided informed consent and followed a link to a self-administered questionnaire. The Freie Universität Berlin approved the procedures.

\section{Measurements}

As in study 2, the assessment of stage was a refinement of the algorithm previously developed for exercise and diet (see "Study 1-Telephone Survey in Hawaii (USA)") in German [37]. Physical activity stage and fruit and vegetable consumption stage were measured as in "Study 2-Online Study in German-Speaking Countries" (see above).

Foot checking stage (important for diabetics to prevent loss of feet due to severe circulatory problems) was measured with the question: "Do you usually check your feet for sores, redness, cuts etc. once a day?" Additionally, alcohol consumption stage was assessed with "Please think about what you typically drink. Do you avoid drinking alcoholic beverages on a daily basis (less than a glass of wine, a bottle of beer or more per day)?" For all behaviors, the instruction followed: "Please choose the statement that describes you best." Participants responded to a rating scale with the verbal anchors "No, and I do not intend to start" (PC), "No, but I am considering it" (C), "No, but I seriously intend to start" $(\mathrm{P})$, "Yes, but this is very difficult for me" (A), and "Yes, and this is very easy for me" (M). Non- smoking stage was assessed by asking about participants' current and past non-smoking habits and by questioning the smokers about their intentions to quit. Participants were classified into one of six stages; PC: smoker with no intention to quit; $\mathrm{C}$ : smoker, who consider to quit; $\mathrm{P}$ : smoker with strong intention to quit; $\mathrm{A} / \mathrm{M}$ : previous smoker who quit; and never-smokers [4, 19].

\section{Results}

\section{Stage Distribution}

For physical activity, the stage distribution was PC, 15 (4.8\%); C, 55 (17.7\%); P, 46 (14.8\%); A, 43 (13.9\%); M, $145(46.8 \%)$, for fruit and vegetable consumption $\mathrm{PC}, 48$ (15.5\%), C, 57 (18.4\%); P, 50 (16.1\%); A, 40 (12.9\%); M, 109 (35.2\%), for non-smoking PC, 9 (2.9\%); C, 23 (7.4\%); P, 26 (31\%); A and M, 96 (31\%); with 146 (47.1\%) never smoked, for alcohol consumption PC, 22 (7.1\%); C, 16 (5.2\%); P, 14 (4.5\%); A, 11 (3.5\%); M, 241 (77.7\%), and for foot checking behavior, PC, 45 (14.5\%); C, 56 (18.1\%); P, 22 (7.1\%); A, 29 (9.4\%); M, 150 (48.4\%).

\section{Relationships of Stages Across Different Behaviors}

The non-parametric correlations between all behaviors are reported in Table 3. The rotated component matrix (converging after three iterations) revealed two rotated factors which explained $28.7 \%$ of the variance (first factor) and $23.8 \%$ of the variance (second factor). As reported in Table 3, the three health-promoting behaviors loaded on one factor, and non-smoking - as in study 1 and 2-as well as alcohol consumption loaded on the other factor. The confirmatory analysis (forcing a two-factors solution) validated the exploratory analysis and revealed similar results.

\section{Clusters of Study Participants}

The two-way cluster analysis generated three groups which contained between $28.2 \%$ and $36.9 \%$ of the included study participants (see Fig. 3) and an Average Silhouette of 0.2 (borderline acceptable cohesion and separation). Smoking stage was the most important variable predicting the group allocation (group 1, PC, 3.6\%; C, 13.6\%; P, 18.2\%; A/M, $28.2 \%$ and never-smoker, 36.4\%; group 2, PC, 6\%; C, $9.5 \% ; \mathrm{P}, 6 \% ; \mathrm{A} / \mathrm{M}, 77.4 \%$ and never-smoker, $1.2 \%$; group 3 , never-smoker, $100 \%$ ). Foot checking was of second importance, followed by nutrition, physical activity, and alcohol stage (for stage frequencies, see Fig. 3; detailed numbers can be obtained from the authors).

Based on the characteristic stage frequencies within the cluster groups, they were labeled according to the behavior 
Table 3 Study 3-Spearman-rho correlations between the five stages across five behaviors

\begin{tabular}{|c|c|c|c|c|c|c|}
\hline & & $\begin{array}{l}\text { Physical } \\
\text { activity stage }\end{array}$ & $\begin{array}{l}\text { Fruit and vegetable } \\
\text { consumption stage }\end{array}$ & $\begin{array}{l}\text { Reduced alcohol } \\
\text { consumption stage }\end{array}$ & $\begin{array}{l}\text { Foot } \\
\text { checking } \\
\text { stage }\end{array}$ & $\begin{array}{l}\text { Non- } \\
\text { smoking } \\
\text { stage }\end{array}$ \\
\hline \multirow[t]{3}{*}{ Physical activity stage } & $r$ & & 0.24 & 0.06 & 0.12 & 0.21 \\
\hline & $p$ & & $<0.01$ & 0.28 & 0.04 & 0.01 \\
\hline & $N$ & & 304 & 304 & 302 & 153 \\
\hline \multirow{3}{*}{$\begin{array}{l}\text { Fruit and vegetable } \\
\text { consumption stage }\end{array}$} & $r$ & & & -0.03 & 0.22 & 0.16 \\
\hline & $p$ & & & 0.62 & $<0.01$ & 0.06 \\
\hline & $N$ & & & 304 & 302 & 153 \\
\hline \multirow{3}{*}{$\begin{array}{l}\text { Reduced alcohol } \\
\text { consumption stage }\end{array}$} & $r$ & & & & 0.02 & 0.07 \\
\hline & $p$ & & & & 0.71 & 0.39 \\
\hline & $N$ & & & & 302 & 153 \\
\hline \multirow[t]{3}{*}{ Foot checking stage } & $r$ & & & & & 0.14 \\
\hline & $p$ & & & & & 0.02 \\
\hline & $N$ & & & & & 153 \\
\hline Factor loading on factor $1^{\mathrm{a}}$ & & 0.62 & 0.75 & - & 0.63 & - \\
\hline Factor loading on factor $2^{\mathrm{a}}$ & & - & - & 0.77 & - & 0.72 \\
\hline
\end{tabular}

${ }^{\mathrm{a}}$ Never-smokers excluded. Factor loadings below 3 are suppressed (VARIMAX rotated principal component factor analysis)

with variance between the groups: individuals in group 1 were changing their health behaviors and not performing any risk behaviors. Those in group 2 already maintained all health behaviors and their cessation from researched risk behaviors. Individuals in group 3 were those who showed a very healthy lifestyle with maximum health behaviors and minimum risk behaviors (see Fig. 3).

\section{General Discussion}

The aim of the three international studies were to investigate multiple health behavior change within the context of (a) the Transtheoretical Model's stages which indicate where an individual is in the process of behavior change. Also, the study was driven by (b) the Theory of Triadic Influences by Flay and Petraitis [2], which explains that similarities between behaviors are related to similar etiologies and experiences of the behaviors. Furthermore, (c) Transfer was a theorized mechanism of how one behavior influences another.

Three theory-based hypotheses were tested in three different studies. The analyses are novel in terms of (1) using the stage-of-change variable when examining correlations, clusters of behaviors, and clusters of individuals regarding their behaviors (and not using only behavior as a continuous or dichotomous measure without motivation). Also innovative was that (2) the two a priori hypothesized factors "health-promoting behaviors" and "health-risk behaviors" were confirmed in the three different data sets.
Correlational Patterns: Which Behaviors are Associated?

In all three studies, the expected pattern emerged: significant correlations (with medium effect sizes, cf. [38]) were found among related behaviors, i.e., within "health-promoting behaviors" (physical activity, nutrition, healthy drinking, foot checking; all above $r=0.11$ ). This and previous findings (from, e.g., [5, 18, 19, 21, 23]) validate the theoretical assumptions from the TTI. Unexpectedly, within the two investigated "health-risk behaviors" (smoking, alcohol consumption), the correlation was small and not significant ( $r=$ 0.07). This is contrary to previous studies (e.g., [5]) and may be related to the sample of study 3: only individuals with diabetes were included.

Low correlations between behaviors which are from different domains was mostly confirmed. Non-smoking and physical activity was correlated between $r=0.01$ and 0.21 in the three studies. All other correlations of the different domains were also within this range. Although some correlations were not as expected, i.e., some behaviors from different domains correlated significantly. However, the correlation coefficients were smaller than between behaviors from the comparable domains. This was in line with previous studies [5, 19, 22-24] and the theoretical assumptions.

Factorial Pattern: Do the Behaviors Load on Two Factors?

The health-promoting behaviors loaded on one factor and the health-risk behaviors loaded on the other factor in all investigated samples. Overall, nutrition, healthy drinking 
(water, juice), exercising, and foot checking constitute the health-promoting behavior factor, and smoking and alcohol consumption represent the health-risk behavior factor. This confirms the theoretical assumptions of the TTI. Comparable findings were reported by Van Nieuwenhuijzen et al. [25] who found in adults a health-promoting behavior factor, a health-risk behavior factor (containing alcohol consumption and unsafe sex), and a delinquency behavior factor. The current study, however, investigated only a limited number of behaviors. Future studies need to include more behaviors, especially more health-risk behaviors like drug abuse or sun exposure. Other behaviors might also be looked at such as road safety, sleep, safer sex, selfexamination, and stress management (as other studies have partially done, see e.g., $[19,25])$.

By doing that, confirmatory analyses could validate the two factors with a broader scope, which is needed for understanding multiple health behavior change [1, 3]. However, the current findings speak for potential transfer effects between the behaviors within one domain.

Individuals Who Cluster Regarding their Behaviors: What are Behavioral Characteristics of the Clusters?

In all three of the studies, three cluster groups were found. All three studies had one group in common which exhibited the maximum number of health behaviors and could be seen as a positive model for the other groups. Although the fit indices were only modest, groups were distinct regarding most behaviors. In general, the clustered groups were characterized by quite positive profiles. In study 1, all groups were physically active and discriminated only by nutrition and smoking. One group was not changing nutrition and not smoking. Looking from the multiple behavior change perspective, this group may have transferred its competencies to be physically active and not to smoke.

Both in study 2 and 3, the majority of group members were maintaining all behaviors or were never-smokers. In study 3, a group maintained all behaviors including nonsmoking (the difference to the "maximum health behaviors group" was that this group had smoked before). In study 2 , a group was found which maintained all behaviors except physical activity, which the group members prepared to adopt. The remaining group in both studies was a group which was characterized by intending to change health behaviors and (already) performing no risk behavior.

Interpretation of Results on Basis of Theoretical Background

If these behavioral patterns are known, multiple health behavior change interventions can be matched to not only one single behavior at a time but to the different behavior and their potential interrelations [2]. Concluding from all three studies, at least three groups should be differentiated: (1) a group with no risk behaviors and motivated to change their health behaviors; (2) a group with no risk behaviors and not considering changing suboptimal health behaviors, and (3) a group that maintains all health (and risk) behaviors. Probably, in other samples, at least one further group should be considered: (4) a group with suboptimal risk- and health behaviors, as these individuals were found in many other studies (e.g., [30]).

The findings from the current studies may be interpreted on basis of transfer: if individuals change one behavior, such as physical activity, other behavior domains like nutrition may benefit [39]. This is especially important in the domain of multiple behaviors: successful modification of one behavior domain can affect changing the other domain possibly by transfer.

\section{Implications for Research and Practice}

The advantage of this study was the investigation of stage: even if a behavior change is not observable, intention might be influenced. However, in future studies, such stage movements should be evaluated longitudinally. Also, to get more insight into possible gate-way behaviors which motivate or push other behaviors, further research is needed.

Cross-sectional studies (as the current ones) make it impossible to identify which behavior may have changed in the past and which behaviors the study participants intend to change in the future. However, regarding transfer, all conclusions are solely based on theoretical assumptions and conclusions from comparisons of people who are assumed to move from one stage (represented by one group) to another stage (represented by another group).

The results and conclusions from these three studies should be tested in prospective and experimental studies with also examining the determinants of the different health behaviors [1, 27, 40]. Addressing multiple behaviors may provide synergistic effects and can increase impact of interventions. However, intervention developers may also be aware of potential reversed transfer, i.e., compensatory effects, which may be happening within intervention participants [9]. This research serves as a starting point in the theoretical understanding of multiple health behaviors.

\section{Conclusions}

This was the first study to investigate patterns across stages of different health behavior domains and the clustering of them on basis of three theories of behavior change across 
three international samples. Health-promoting behaviors (physical activity, nutrition, etc.) and health-risk behaviors (smoking and alcohol) cluster. This has implications for how to tailor interventions, not only to one behavior at a time, but to target multiple behaviors more efficiently. In general, more theory-driven analyses should replicate and extend the observed patterns. For the improvement of a healthy lifestyle, transfer effects might be a strategy to increase multiple health behaviors.

Open Access This article is distributed under the terms of the Creative Commons Attribution Noncommercial License which permits any noncommercial use, distribution, and reproduction in any medium, provided the original author(s) and source are credited.

\section{References}

1. Prochaska JJ, Spring B, Nigg CR. Multiple health behaviour change research: an introduction and overview. Prev Med. 2008;46:181-8.

2. Flay BR, Petraitis J. The theory of triadic influence. Advances in Medical Sociology. 1994;4:19-44.

3. Morabia A, Costanza MC. Multiple health behavior change interventions: tell us what you see. Prev Med. 2010;50:1-2.

4. Prochaska JO, DiClemente CC. Stages and processes of selfchange of smoking: toward an integrative model of change. J Consult Clin Psychol. 1983;51(3):390-5.

5. Keller S, Maddock JE, Hannöver W, Thyrian JR, Basler H-D. Multiple health risk behaviors in German first year university students. Prev Med. 2008;46:189-95.

6. Thorndike EL, Bregman EO, Tilton JW, Woodyard E. Adult learning. New York: Macmillan; 1928.

7. Perkins DN, Salomon G. Transfer of learning. In: Husen T, Postlethwaite TN, editors. The international encyclopedia of education (2nd ed., vol. 11). Oxford: Pergamon. 1992. p. 6452-6457.

8. Barnett SM, Ceci SJ. When and where do we apply what we learn? A taxonomy for far transfer. Psychol Bull. 2002;128:612-37.

9. Knäuper B, Rabiau M, Cohen O, Patriciu N. Compensatory health beliefs: scale development and psychometric properties. Psychol Health. 2004;19(5):607-24.

10. Mata J, Silva MN, Vieira PN, Carraca EV, Andrade AM, Coutinho SR, et al. Motivational "spill-over" during weight control: Increased self-determination and exercise intrinsic motivation predict eating self-regulation. Health Psychol. 2009;2:709-16.

11. Ussher MH, West R, McEwen A, Taylor A, Steptoe A. Randomized controlled trial of physical activity counseling as an aid to smoking cessation: 12 month follow-up. Addict Behav. 2007;32:3060-4.

12. Wilcox S, King AC, Castro C, Bortz W. Do changes in physical activity lead to dietary changes in middle and old age? Am J Prev Med. 2000;18:276-83.

13. Prochaska JJ, Sallis JF. A randomized controlled trial of single versus multiple health behavior change: promoting physical activity and nutrition among adolescents. Health Psychol. 2004;23(3):314-8.

14. Weinstock J, Barry D, Petry NM. Exercise-related activities are associated with positive outcome in contingency management treatment for substance use disorders. Addict Behav. 2008;33: $1072-5$.
15. Prochaska JO, Velicer WF, Rossi JS, Redding CA, Greene GW, Rossi SR, et al. Multiple risk expert systems interventions: impact of simultaneous stage-matched expert system interventions for smoking, high fat diet, and sun exposure in a population of parents. Health Psychol. 2004;23:503-16.

16. Koelewijn-van Loon MS, van der Weijden T, Ronda G, van Steenkiste B, Winkens B, Elwyn G, et al. Improving lifestyle and risk perception through patient involvement in nurse-led cardiovascular risk management: a cluster-randomized controlled trial in primary care. Prev Med. 2010;50:35-44.

17. Werch CE, Moore MJ, Bian H, DiClemente CC, Huang I-C, Ames SC, et al. Are effects from a brief multiple behavior intervention for college students sustained over time? Prev Med. 2010;50:30-4.

18. Grant N, Wardle J, Steptoe A. The relationship between life satisfaction and health behavior: a cross-cultural analysis of young adults. Int J Behav Med. 2009;16:259-68.

19. Nigg CR, Burbank PM, Padula C, Dufresne R, Rossi JS, Velicer WF, et al. Stages of change across ten health risk behaviors for older adults. Gerontologist. 1999;39(4):473-82.

20. Wilson DB, Smith BN, Speizer IS, Bean MK, Mitchell KS, Uguy LS, et al. Differences in food intake and exercise by smoking status in adolescents. Preventive Medicine: An International Journal Devoted to Practice and Theory. 2005;40:872-9.

21. Boudreaux ED, Wood KB, Mehan D, Scarinci I, Taylor CL, Brantley PJ. Congruence of readiness to change, self-efficacy, and decisional balance for physical activity and dietary fat reduction. Am J Health Promot. 2003;17:329-36.

22. Clements Thompson M, Klesges RC, Haddock K, Lando H, Talcott W. Relationships between stages of change in cigarette smokers and healthy lifestyle behaviors in a population of young military personnel during forced smoking abstinence. J Consult Clin Psychol. 1998;66:1005-11.

23. Boudreaux ED, Francis JL, Carmack Taylor CL, Scarinci IC, Brantley PJ. Changing multiple health behaviors: smoking and exercise. Prev Med. 2003;36:471-8.

24. Abrantes AM, Lee CS, MacPherson L, Strong DR, Borrelli B, Brown RA. Health risk behaviors in relation to making a smoking quit attempt among adolescents. J Behav Med. 2009;32:142-9.

25. Van Nieuwenhuijzen M, Junger M, Klein Velderman M, Wiefferink KH, Paulussen TWGM, Hox J, et al. Clustering of healthcompromising behavior and delinquency in adolescents and adults in the Dutch population. Prev Med. 2009;48:572-8.

26. Verkooijen KT, Nielsen GA, Kremers SPJ. Leisure time physical activity motives and smoking in adolescence. Psychology of Sport and Exercise. 2009;10:559-64.

27. Kremers SPJ, de Bruijn G-J, Schaalma H, Brug J. Clustering of energy balance related behaviours and their intrapersonal determinants. Psychol Health. 2004;19:595-606.

28. Dodd LJ, Al-Nakeeb Y, Nevill A, Forshaw MJ. Lifestyle risk factors of students: a cluster analytical approach. Prev Med. 2010;51:73-7.

29. Quintiliani L, Allen J, Marino M, Kelly-Weeder S, Li Y. Multiple health behavior clusters among female college students. Patient Educ Couns. 2010;79:134-7.

30. DeVries H, van't Riet J, Spigt M, Metsemakers J, van den Akker M, Vermunt JK, et al. Clusters of lifestyle behaviors: results from the Dutch SMILE study. Prev Med. 2008;46:203-8.

31. Norušis MJ. PASW Statistics 18 statistical procedures companion. Upper Saddle River: Pearson; 2010.

32. Maddock J, Marshall C, Nigg C, Barnett J. Development and first year results of a psychosocial surveillance system for chronic disease related health behaviors. Californian Journal of Health Promotion. 2003;1:54-64.

33. Nigg CR, Maddock JE, Yamauchi J, Pressler V, Wood B, Jackson S. The healthy Hawaii initiative: a social ecological approach 
promoting healthy communities. Am J Health Promot. 2005; 19:310-3.

34. Hellsten L, Nigg C, Norman G, Burbank P, Braun L, Breger R, et al. Accumulation of behavioral validation evidence for physical activity stage of change. Health Psychol. 2008;27 (Suppl):S43-53.

35. Greene GW, Nancy F-Y, Padula C, Rossi S, Rossi JS, Clark PG. Differences in psychosocial variables by stage of change for fruits and vegetables in older adults. J Am Diet Assoc. 2004;104:1236-43.

36. Rademacher JDM, Lippke S. Dynamic online surveys and experiments with the free open source software dynQuest. Behav Res Meth. 2007;39(3):415-26.
37. Lippke S, Ziegelmann JP, Schwarzer R, Velicer WF. Validity of stage assessment in the adoption and maintenance of physical activity and fruit and vegetable consumption. Health Psychol. 2009;28(2):183-93.

38. Cohen J. A power primer. Psychol Bull. 1992;112:155-9.

39. French SA, Hennrikus DJ, Jeffery RW. Smoking status, dietary intake, and physical activity in a sample of working adults. Health Psychol. 1996;15(6):448-54.

40. Peters LWH, Wiefferink CH, Hoekstra F, Buijs GJ, ten Dam GTM, Paulussen TGWM. A review of similarities between domain-specific determinants of four health behaviors among adolescents. Health Educ Behav. 2009;24:189-223. 